\title{
Circulation changes in the winter lower atmosphere and long-lasting solar/geomagnetic activity
}

\author{
J. Bochníček ${ }^{1}$, H. Davídkovová ${ }^{1,2}$, P. Hejda ${ }^{1}$, and R. Huth ${ }^{2,3}$ \\ ${ }^{1}$ Institute of Geophysics, Academy of Sciences of the Czech Republic, Boční II/1401, 14131 Prague, Czech Republic \\ ${ }^{2}$ Faculty of Science, Charles University, Albertov 6, 12843 Prague, Czech Republic \\ ${ }^{3}$ Institute of Atmospheric Physics, Academy of Sciences of the Czech Republic, Boční II/1401, 14131 Prague, \\ Czech Republic
}

Correspondence to: J. Bochníček (jboch@ig.cas.cz)

Received: 3 May 2012 - Revised: 26 September 2012 - Accepted: 4 December 2012 - Published: 19 December 2012

\begin{abstract}
The paper describes the association between high long-lasting solar/geomagnetic activity and geopotential height (GPH) changes in the winter lower atmosphere, based on their development in the Northern Hemisphere in the winter periods (December-March) of 1950-1969 and 19702002. Solar/geomagnetic activity is characterised by the 60 day mean of the sunspot number R/by the 60-day mean of the daily sum of the Kp index. The GPH distributions in the lower atmosphere are described by 60-day anomalies from their long-term daily average at $20 \mathrm{hPa} / 850 \mathrm{hPa}$. The data have been adopted from the NCEP/NCAR reanalysis. The 60-day mean values of solar/geomagnetic activity and GPH anomalies were calculated in five-day steps over the whole winter period. The analysis was carried out using composite maps which represent their distribution of the GPH anomalies during high solar activity $(R \geq 100)$ and high geomagnetic activity $(\Sigma K \mathrm{~K} \geq 20)$. Analysis has shown that the distribution of GPH anomalies depends on solar activity, geomagnetic activity and the phase of winter period (early or late winter). The nature of this relationship then depends on the time interval involved, i.e. 1950-1969 or 1970-2002. Positive anomalies in the polar stratosphere $(20 \mathrm{hPa})$ were detected during the whole winter periods of the years 19501969. Significant anomalies were detected in the lower troposphere $(850 \mathrm{hPa})$ during the second half of the winter period. The distribution of GPH anomalies on the maps compiled with regard to solar activity was similar to the distribution on maps compiled with regard to geomagnetic activity. In the interval 1970-2002, significant negative GPH anomalies were detected in the stratosphere at high latitudes, and positive anomalies were detected in the region of low latitudes.
\end{abstract}

The distribution of GPH anomalies in the lower troposphere was substantially affected by situations in which, together with high solar activity, also high geomagnetic activity occurred.

Keywords. Magnetospheric physics (General or miscellaneous) - Meteorology and atmospheric dynamics (General circulation) - Solar physics, astrophysics, and astronomy (General or miscellaneous)

\section{Introduction}

A number of papers have dealt with the connection between the distribution of pressure and temperature fields in the winter atmosphere and solar activity (Labitzke and van Loon, 1988; van Loon and Labitzke, 1988; Barnston and Livezey, 1989, 1991; Kodera, 1991, 2003; Balachandran and Rind, 1995; Rind and Balachandran, 1995; Balachandran et al., 1999; Haigh, 1994, 1996, 2003; Gleisner and Thejll, 2003; Gimeno et al., 2003; Kodera and Kuroda, 2005; Gray et al., 2010; and Marchand et al., 2012). The influence of geomagnetic activity has been overlooked for a long time. One of the reasons was the widely accepted idea that geomagnetic activity is a mere derivative of solar activity. Recent studies, however, indicate that geomagnetic activity is a correlator just as significant as solar activity (Bucha and Bucha Jr., 1998; Bochníček et al., 1999a, b; Bochníček and Hejda, 2002, 2005; Boberg and Lundstedt, 2002, 2003; Thejll et al., 2003; Lu et al., 2007, 2008a, b; Li et al., 2011; Woollings et al., 2010). The aim of this study is to compare the effects of both activities on atmospheric circulation on a 
time scale shorter (60-days) than used in the previous studies. In view of the number of papers, in which the authors pointed out the change in the nature of the relationship between solar activity, or the parameters related to solar activity, and the distribution of the GPH anomalies in the northern winter lower atmosphere around the year 1970 (Thompson et al., 2000, 2010; Boberg and Lundstedt, 2002; Thejll et al., 2003; Li et al., 2011), we divided the interval 1950-2002 and we investigated, as in Thejll et al. (2003), the two parts: 19501969 and 1970-2002. The relationship between the GPH distribution in the lower atmosphere $(20 \mathrm{hPa}, 850 \mathrm{hPa})$ and solar/geomagnetic activity was analysed by means of composite maps. Attention was also devoted to the evolution of this relationship in the course of the winter period (DecemberMarch). The effect of the quasi-biennial oscillation (QBO) was not studied.

\section{Data and methods}

The geopotential height data (GPH) of winter periods (December-March) 1950-2002 were obtained from NCEP/NCAR reanalysis data, Boulder, USA. Long-term daily averages of GPH at levels of $20 \mathrm{hPa}$ and $850 \mathrm{hPa}$ were computed on the basis of the 1950-2002 winter periods. The values of daily GPH anomalies in the analysed interval, 1950-2002, were computed by subtracting the respective daily values of GPH from their long-term daily average. Obtained GPH anomalies were used to compile a series of 60-day daily averages spaced at 5-day intervals The composite maps of the 60-day anomalies, created on the basis of solar/geomagnetic activity data, were compiled so that each studied 60-day interval contained all cases which are characterised by an average 60-day value of $R$ higher or equal to 100 , and $\Sigma \mathrm{Kp}$ higher or equal to $20 . R$ is sunspot number and $\Sigma \mathrm{Kp}$ is the daily sum of geomagnetic Kp indices. The values of sunspot number $R$ and of geomagnetic Kp index were adopted from the NOAA Geophysical Data Center, Boulder, USA.

The relevance of the GPH anomalies was estimated using the Monte Carlo trial-based nonparametric test ( $\mathrm{Lu}$ et al., 2007). The procedure consists of selecting a large number (10000 in our study) of random samples from the original data set of GPH anomalies and constructing their distribution. The composite map is then compared to this distribution, and its rank among these randomized trials is computed. As it can be hardly assumed that the samples are uncorrelated in space and time, this procedure does not give an exact level of statistical significance. It just highlights regions which should be paid more attention to.

\section{Results}

\subsection{0-day analysis}

The relationship between solar/geomagnetic activity and the distribution of GPH anomalies in the lower stratosphere $(20 \mathrm{hPa})$ and lower troposphere $(850 \mathrm{hPa})$ in winter (December-March) in the years 1950-1969 and 1970-2002 was analysed by means of a series of overlapping (steps of 5 days) 60-day composite maps. Solar activity was expressed in terms of 60-day averages of the sunspot number $R$ and geomagnetic activity in terms of 60-day averages of daily sums of Kp indices. To keep the length of the paper down, only five 60 -day periods are in this paper presented. The values of the corresponding 60-day averages of both activities are given in Table 1 (see supplement). The configuration of the stratospheric/tropospheric GPH anomalies at the time of high solar/geomagnetic activity was studied in the time intervals 1 December-29 January, 16 December-13 February, 31 December-28 February, 15 January-15 March and 30 January-30 March. The results relating to the stratosphere in the interval of years 1950-1969 are displayed in Fig. 1; the results relating to the troposphere are displayed in Fig. 2. The results relating to the stratosphere in the interval of years 1970-2002 are displayed in Fig. 3, the results relating to the troposphere are displayed in Fig. 4.

\subsubsection{Interval of years 1950-1969}

In the stratosphere was high solar as well as high geomagnetic activity associated with the occurrence of significant positive GPH anomaly in the polar region (see Fig. 1a, b). The analysis of the separate composite maps (spaced at 5day intervals) describing the distribution GPH anomalies in the troposphere indicated that the occurrence of pronounced GPH anomalies, associated with a particular region of the Northern Hemisphere during the winter period, can only be observed in the second half of the winter period.

On the maps constructed with regard to solar activity, such an anomaly is the negative anomaly over the mid-latitude Atlantic, together with the positive anomaly over the northern Atlantic and the polar region in the intervals 31 December28 February and 15 January-15 March (see Fig. 2a).

In the maps constructed with regard to geomagnetic activity, in the second half of the winter period one can observe namely positive GPH anomalies over Siberia and the Pacific, together with negative GPH anomalies over the eastern Atlantic and central Asia in the intervals 15 January-15 March and 30 January-30 March (see Fig. 2b).

\subsubsection{Interval of years 1970-2002}

60-day intervals with high solar activity $(R \geq 100)$, as well as 60 -day intervals with high geomagnetic activity $(\Sigma \mathrm{Kp} \geq 20)$, occur in the interval 1970-2002 frequently enough to be able to select a sufficient number of situations with $(R \geq 100$; 
(a)

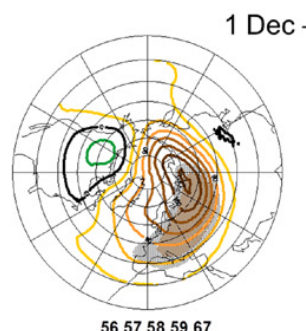

Dec - 29 Jan

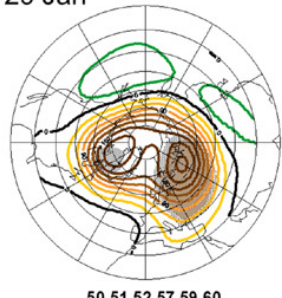

$16 \mathrm{Dec}-13 \mathrm{Feb}$
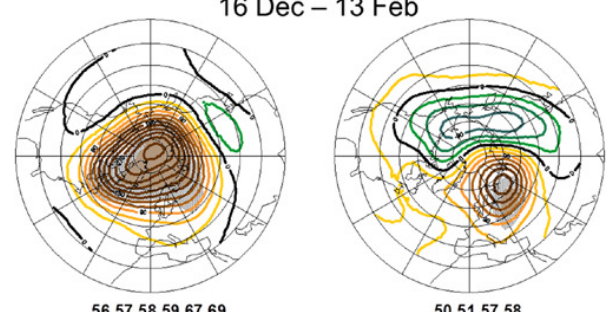

$31 \mathrm{Dec}-28 \mathrm{Feb}$
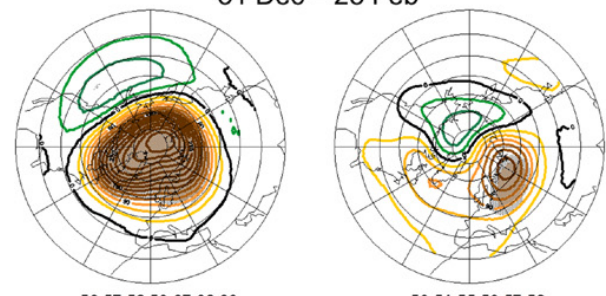

56575859676869

15 Jan - 15 Mar
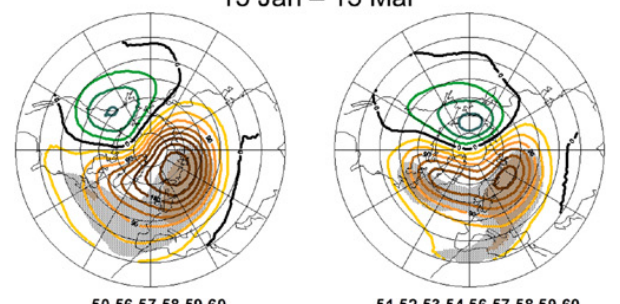

$30 \mathrm{Jan}-30 \mathrm{Mar}$
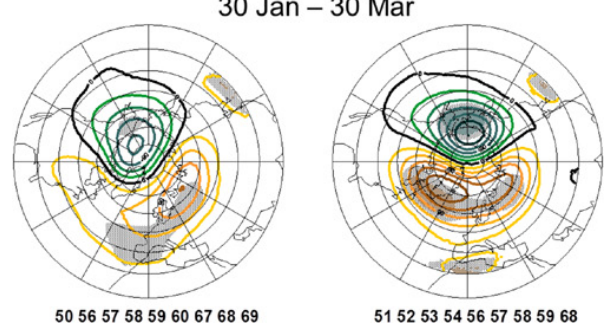

Fig. 1. Stratosphere in the years 1950-1969. Composite maps of 60-day winter (December-March) mean values of GPH anomalies at the geopotential level of $20 \mathrm{hPa}$ under: (a) high solar activity $(R \geq 100)$ and (b) high geomagnetic activity $(\Sigma \mathrm{Kp} \geq 20)$. GPH anomalies were computed from the long-term (1950-2002) average. The caption above each map indicates the beginning and end of the selected period. The pairs of numbers below each map indicate the year in which the particular 60-day period started. Positive anomalies are plotted as yellow-brown lines and negative anomalies as green-blue lines. The contour interval is $30 \mathrm{~m}$. Shadings indicate areas where the Monte Carlo test introduced in Sect. 2 gave highest score. (a)

(b)
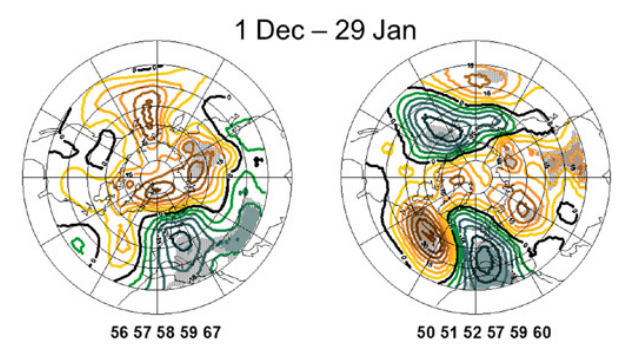

$16 \mathrm{Dec}-13 \mathrm{Feb}$

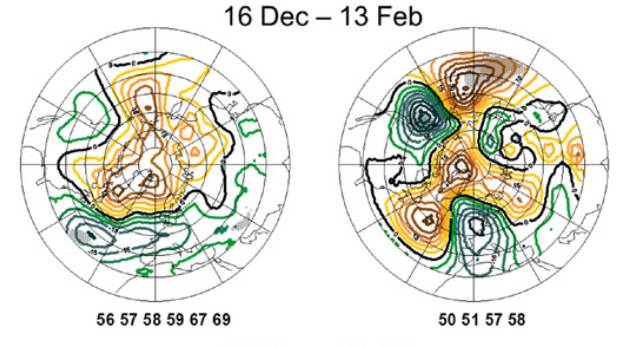

$31 \mathrm{Dec}-28 \mathrm{Feb}$
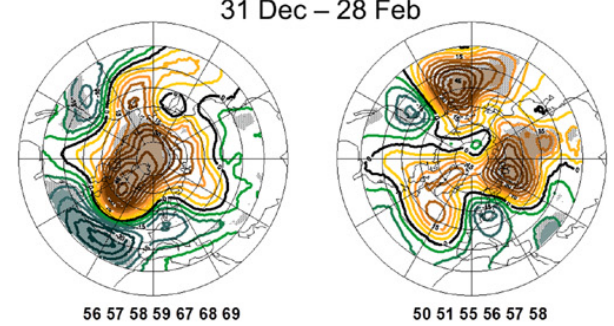

$15 \mathrm{Jan}-15 \mathrm{Mar}$
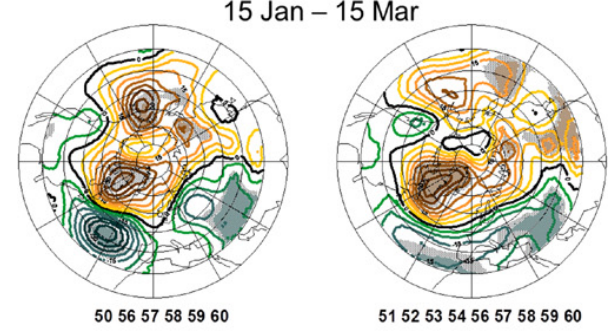

$30 \mathrm{Jan}-30 \mathrm{Mar}$
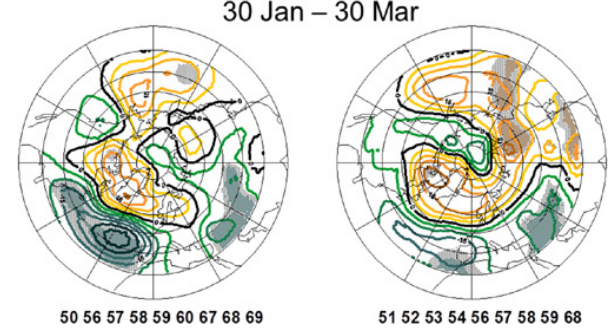

Fig. 2. Troposphere in the years 1950-1969. As in Fig. 1, but for geopotential level $850 \mathrm{hPa}$. The contour interval is $5 \mathrm{~m}$.

$\Sigma \mathrm{Kp}<20),(R<100 ; \Sigma \mathrm{Kp} \geq 20)$ and $(R \geq 100 ; \Sigma \mathrm{Kp} \geq 20)$ from these 60-day intervals. The magnitude of the effect of the individual activities on the distribution of the GPH anomalies can then be estimated with the use of the composite maps, which were constructed with regard to these activity situations.

Each of these activity situations mentioned above is then associated in the stratosphere with a different distribution 
(a)
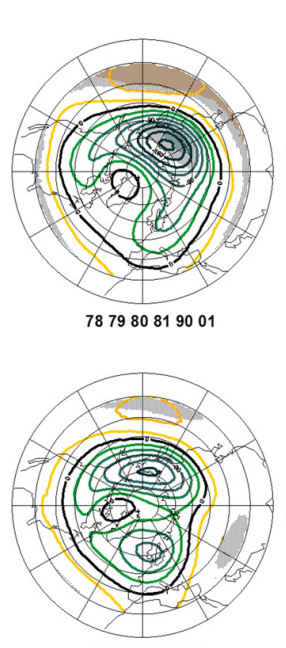

7879809001

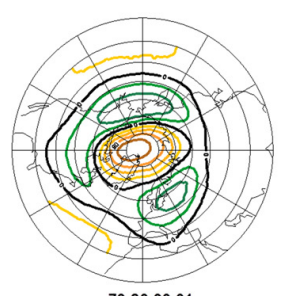

79809001
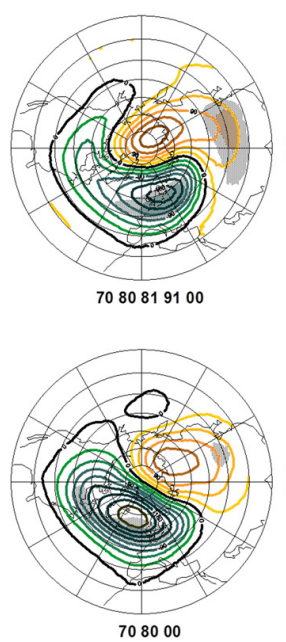

(b)

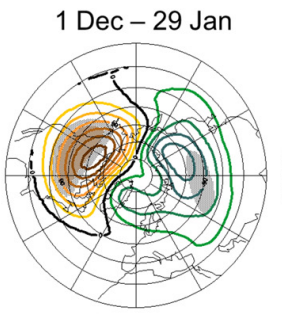

7482849293

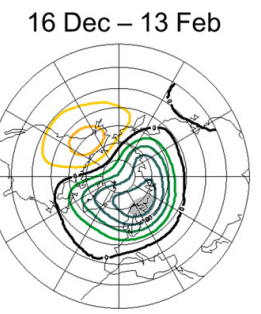

747578828485929302

$31 \mathrm{Dec}-28 \mathrm{Feb}$

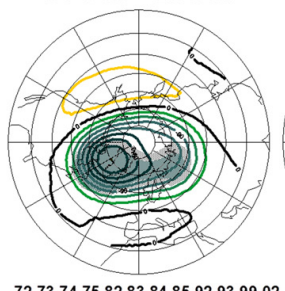

727374758283848592939902
15 Jan - 15 Mar

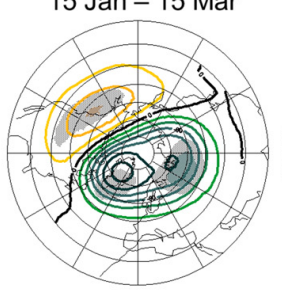

73747576838485869394 30 Jan - 30 Mar

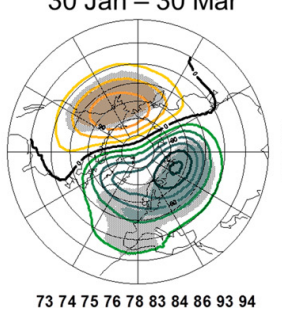

(c)
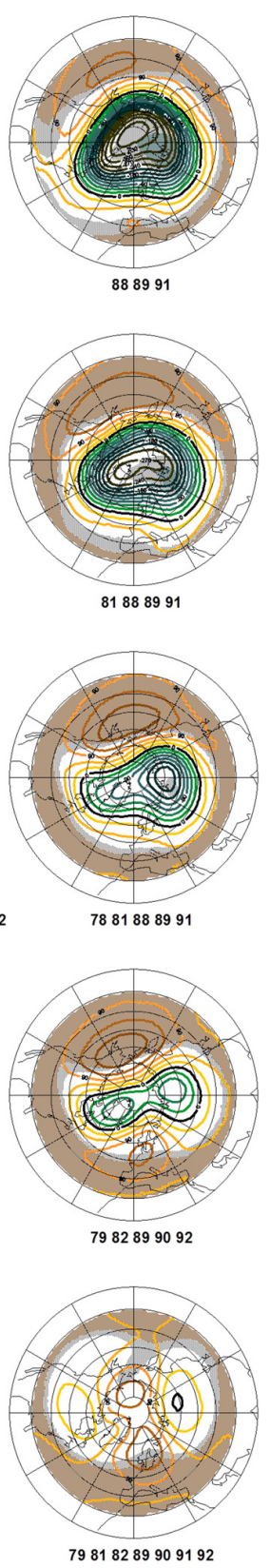

Fig. 3. Stratosphere in the years 1970-2002. As in Fig. 1, but for (a) situations, in which the effect of the geomagnetic activity was decreased $(R \geq 100 ; \Sigma \mathrm{Kp}<20)$, (b) situations, in which the effect of solar activity was decreased $(R<100 ; \Sigma \mathrm{Kp} \geq 20)$, (c) situations, in which, together with high solar activity, also high geomagnetic activity $(R \geq 100 ; \Sigma \mathrm{Kp} \geq 20)$ was observed.

of pronounced anomalies. The composite maps, constructed with a view to the situations, in which the effect of the geomagnetic activity was decreased $(R \geq 100 ; \Sigma \mathrm{Kp}<20)$ displayed the occurrence of significant negative anomalies at high latitudes and the occurrence of significant posi-

(a)
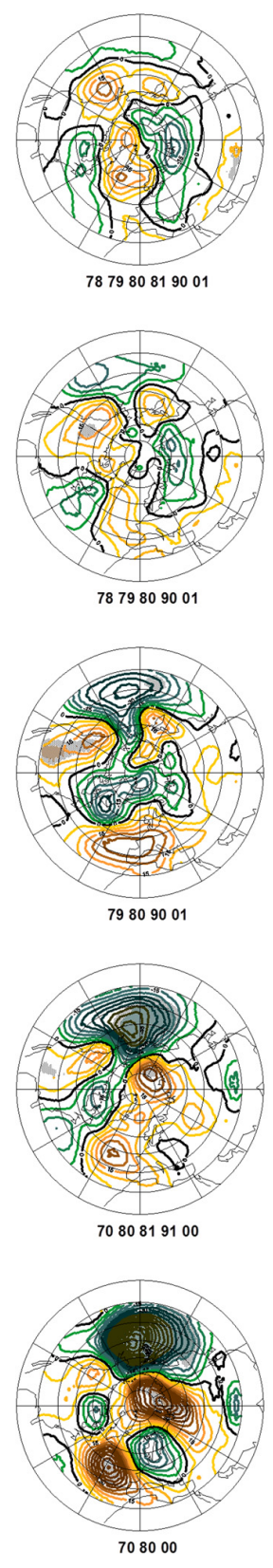

Fig. 4. Troposphere in the years 1970-2002. As in Fig. 3, but for geopotential level $850 \mathrm{hPa}$. The contour interval is $5 \mathrm{~m}$.

tive anomalies at low latitudes. The occurrence of negative anomalies was recorded in the intervals of 1 December29 January, 15 January-15 March and 30 January-30 March, and the occurrence of positive anomalies, with exception of the interval of 31 December-28 February, was observed in all the remaining intervals (see Fig. 3a).

The composite maps, constructed with regard to the situations in which, on the contrary, the effect of solar activity was decreased $(R<100 ; \Sigma \mathrm{Kp} \geq 20)$ displayed the occurrence in 
particular pronounced negative anomalies at high latitudes. The occurrence of such anomalies was observed in all the intervals analysed (see Fig. 3b).

The composite maps, constructed with regard to the situations in which, together with high solar activity, also high geomagnetic activity $(R \geq 100 ; \Sigma \mathrm{Kp} \geq 20)$ was observed, displayed the occurrence of pronounced anomalies; negative anomalies observed at high latitudes in the intervals 1 December-29 January, 16 December-13 February and 31 December-28 February, and positive anomalies observed at low latitudes in all intervals analysed (see Fig. 3c).

In the troposphere, the distributions of the GPH anomalies, constructed with regard to the situations, differ substantially. According to the composite maps, constructed with regard to the situations with $(R \geq 100 ; \Sigma \mathrm{Kp}<20)$ significant anomalies occurred only in the last two intervals: 15 January15 March and 30 January-30 March. These anomalies were negative anomalies over the Pacific (see Fig. 4a).

The composite maps, constructed with regard to the situations with $(R<100 ; \Sigma \mathrm{Kp} \geq 20)$ on the contrary, displayed the occurrence of significant anomalies in all the intervals analysed. The anomalies were negative over the northern Atlantic and the positive over the eastern Atlantic at midlatitudes (see Fig. 4b).

As regards the composite maps, constructed with regard to the situations with $(R \geq 100 ; \Sigma \mathrm{Kp} \geq 20)$, it was found that the occurrence of pronounced, extensive in area, anomalies, varying in location and extent during the winter period was typical. In the first two intervals, 1 December29 January and 16 December-13 February, these anomalies were the negative anomaly over the polar region and the positive anomalies over south-western Europe, the western Mediterranean, and the eastern and western Pacific. During the third interval (31 December-28 February) the extent of the negative anomaly diminished. It now occurred in regions whose centres were over Greenland and the northern part of the Eurasian continent. The positive anomaly over southwestern Europe and the Mediterranean did not change its position; the positive anomaly over the eastern Pacific moved to the west and became connected with the positive anomaly over the western Pacific. In the fourth interval (15 January15 March) the position of the negative anomaly, with regard to the foregoing case, did not change, the centre of the positive anomaly moved from its position over south-western Europe and the western Mediterranean to the east, and the position of the positive anomaly over the central and western Pacific remained unchanged. In the fifth interval (30 January30 March) the negative anomaly remained stable, bar the diminishing of its extent over the northern Eurasian continent. The positive anomaly over southern Europe and the eastern Mediterranean was joined by the region over the eastern Atlantic, the south of the North American continent and the region over the Aleutians. The positive anomaly over the central and western Pacific diminished its area considerably (see Fig. 4c).

\section{Discussions}

The composite maps of the GPH anomalies in the lower stratosphere, shown in Fig. 1a and b, indicate that the high solar and high geomagnetic activity in 1950-1969 were associated with the occurrence of a pronounced positive GPH anomaly in the polar region. In the last 60-day interval (30 January-30 March) of the winter period (DecemberMarch) this anomaly was joined by a negative GPH anomaly. The connection described between the high geomagnetic activity and the occurrence of the positive GPH anomaly in the lower polar stratosphere agrees with the results of the paper by Thejll et al. (2003), which pointed out this relationship, existing in the years 1948-1973, in a correlation map.

In 1950-1969, a signal can be found in the lower troposphere $(850 \mathrm{hPa})$ associated with high solar and/or geomagnetic activity only in the second half of the winter period. The composite maps, constructed with regard to solar activity, indicate that the distribution of the GPH anomalies in this part of the winter resemble the negative phase of the North Atlantic Oscillation (NAO) (see Fig. 2a).

The composite maps, constructed with regard to geomagnetic activity, indicate the occurrence of pronounced positive anomalies, distributed over the eastern part of the Northern Hemisphere. The GPH anomalies, whose distribution resembles the negative phase of the NAO, were observed only in the interval of 15 January-15 March (see Fig. 2b). The occurrence of these GPH anomalies is contrary to one of the results of the paper by Thejll et al. (2003) according to which no signal was observed in the lower troposphere in the years 1948-1973; the source of which could have been geomagnetic activity. This discord can be explained by the correlation map in the referenced paper, which described the relationship between the tropospheric GPH and geomagnetic activity, being constructed for the whole four-month period (December-March), whereas the signal described above was detected in this paper only in a few 60-day intervals.

The composite maps of the GPH anomalies in the lower stratosphere, shown in Fig. 3a-c, indicate that the significant anomalies in the years 1970-2002 were the negative anomaly in the polar region and the positive anomaly in the middle and lower latitudes. The occurrence of the negative anomaly was connected mainly with the occurrence of high geomagnetic activity and the occurrence of positive anomaly with high solar activity. The connection of the occurrence of the negative anomaly with geomagnetic activity in the composite maps in Fig. $3 b$ and $c$ is in accord with the relationship between geomagnetic index Ap and the GPH in the lower stratosphere, which was expressed by the correlation map in the paper by Thejll et al. (2003).

The explanation of the occurrence of positive GPH anomalies at lower and middle latitudes can be found in the paper of Kodera (2006) and Matthes et al. (2006). According to these authors, high solar activity attenuates the BrewerDobson (BD) circulation. Weaker BD circulation means 
weaker upwelling in the equatorial lower stratosphere. This would result in positive ozone anomalies, and hence produce a positive temperature anomaly through adiabatic heating. The positive temperature anomaly is reflected in increase anomalous GPH values in this region.

The composite maps in Fig. 4a-c indicate that significant anomalies essentially occurred in the lower troposphere in the years $1970-2002$ in the cases of $(R<100 ; \Sigma K p \geq 20)$ and ( $R \geq 100 ; \Sigma \mathrm{Kp} \geq 20)$, i.e. in connection mostly with geomagnetic activity (see Fig. $4 \mathrm{~b}$ and c). The distribution of the GPH anomalies above the Atlantic in the composite maps, constructed with regard to the two above cases, resemble the positive phase of the NAO. The composite maps, constructed from the $(R \geq 100 ; \Sigma \mathrm{Kp}<20)$ data set, i.e. the data set in which the effect of geomagnetic activity was partly suppressed, displayed no stable and distinct signal in the course of the winter period, which could be associated with solar activity over the Atlantic. This result, which agrees with the conclusions of the paper by Li et al. (2011) apparently contradicts the conclusions of Kodera and Kuroda (2002), Kuroda and Kodera (2002) and Kodera (2003) associating solar activity and the NAO. This apparent discord can be explained by means of composite maps, constructed from the $(R \geq 100 ; \Sigma \mathrm{Kp} \geq 20)$ data set and shown in Fig. 4c. Indeed Fig. $4 \mathrm{a}$ and c clearly indicate that the close connection between solar activity and the NAO occurs when this activity is very high. Since the periods of very high solar activity and very high geomagnetic activity coincide (see Table 1), the conclusions in the papers, associating solar activity and the $\mathrm{NAO}$, may be considered as conclusions of papers associating the effect of both high activities, solar and geomagnetic. If we compare the measure of association between the occurrence of significant anomalies in the lower troposphere and the separate activities in the years 1970-2002, i.e. if we compare the composite maps in Fig. $4 \mathrm{a}, \mathrm{b}$ and $\mathrm{c}$, it appears that the closer association is with geomagnetic activity.

The Sun influences the atmosphere by variations in its ultraviolet (UV) radiation. These UV radiation fluctuations can induce significant changes in stratospheric temperature and ozone. Variations in both ozone and temperature in the stratosphere could induce wind anomalies and therefore influence the propagation of planetary waves in the winter hemisphere as well as significant dynamical changes on the global scale (for more details see Balachandran and Rind, 1995; Balachandran et al., 1999; Haigh, 1996, 2003; Gray et al., 2010, and Marchand et al., 2012).

The mechanism, which could explain the effect of geomagnetic activity on the processes in the lower atmosphere, can be found in the literature of recent years. To name but a few: (a) Lundstedt (1984) and Tinsley (2000) according to whom the solar wind modulates the current flow in the global electric circuit, evidently causing changes in the temperature and wind dynamics of the troposphere; (b) Boberg and Lundstedt (2002) providing, in accord with Richmond and Thayer (2000), an answer in the solar-wind generated electromag- netic disturbance in the ionosphere which dynamically propagates downward through the atmosphere; (c) Lu et al. (2007, 2008a, b) and Seppälä et al. (2009) describing the effects of energetic particle precipitations (EPP) associated with geomagnetic activity on the processes in the lower atmosphere; Arnold and Robinson (2001) claiming that the warming in the lower thermosphere, caused by geomagnetic activity, reduces the blending of mid- and high-latitude air masses. In consequence of this reduction, the temperature of the solar insulated region (polar lower stratosphere) decreases. In spite of the number of mechanisms mentioned above, more detailed studies will be required, which would provide a better understanding of the relationship between geomagnetic activity and the changes in circulation in the lower atmosphere.

\section{Conclusions}

The analysis of the composite maps, constructed with regard to high solar and high geomagnetic activity, has shown that:

1. High values of solar activity, as well as high values of geomagnetic activity in 1950-1969 were associated with the occurrence of significant positive GPH anomaly in the lower polar stratosphere. In the lower troposphere, in the second half of the winter period, high values of both activities were associated with the occurrence of pronounced GPH anomalies, the distribution of which resembled the negative phase of the NAO.

2. In 1970-2002, high values of solar activity, with the exception of cases in which high solar activity occurred together with high geomagnetic activity, i.e. the values of solar activity from the set $(R \geq 100 ; \Sigma \mathrm{Kp}<20)$ associated with the occurrence of a negative GPH anomaly in the lower polar stratosphere at the beginning and end of the winter period. In the lower troposphere in the second half of the winter period, these values of solar activity were associated with the occurrence of negative GPH anomalies over the Pacific.

3. In 1970-2002, high values of geomagnetic activity, with the exception of cases in which high geomagnetic activity occurred together with high solar activity, i.e. the values of geomagnetic activity from the set $(R<100$; $\Sigma \mathrm{Kp} \geq 20$ ) were associated with the occurrence of a negative GPH anomaly in the lower stratosphere in the course of the whole winter period. In the lower troposphere, these values of geomagnetic activity were associated with the occurrence of pronounced GPH anomalies, the distribution of which resembled the positive phase of the NAO.

4. In 1970-2002, high values of solar and geomagnetic activity occurred simultaneously, i.e. the values of the activities from the set $(R \geq 100 ; \Sigma \mathrm{Kp} \geq 20)$ were associated, with the exception of the end of the winter period, 
with the occurrence of a negative GPH anomaly in the lower polar stratosphere. In the lower troposphere, in the course of the whole winter period, the values of both activities were associated with the occurrence of pronounced GPH anomalies, the distribution of which resembled the positive phase of the NAO and the seesaw pattern between the Mediterranean and the Russian regions.

5. The composite maps, constructed from the sets $(R \geq$ 100; $\Sigma \mathrm{Kp}<20),(R<100 ; \Sigma \mathrm{Kp} \geq 20)$ and $(R \geq 100$; $\Sigma K p \geq 20$ ) clearly indicate that, in 1970-2002, changes occurred in the distribution of the anomalous GPH values over the Atlantic and Eurasia, mainly in connection with the change of geomagnetic and not solar activity. A close relationship between solar activity and the changes of atmospheric fields in the lower troposphere can be explained by the temporal concurrence of high values of solar and geomagnetic activity.

\section{Supplementary material related to this article is available online at: http://www.ann-geophys.net/30/1719/ 2012/angeo-30-1719-2012-supplement.pdf.}

Acknowledgements. This work was supported by Grant IAA300420805 of the Grant Agency of the Academy of Sciences of the Czech Republic and by the Ministry of Education, Youth, and Sports of the Czech Republic under grant LD12053, and OC09070.

Topical Editor P. Drobinski thanks two anonymous referees for their help in evaluating this paper.

\section{References}

Arnold, N. F. and Robinson, T. R.: Solar magnetic flux influences on the dynamics of the winter middle atmosphere, Geophys. Res. Lett., 28, 2381-2384, doi:10.1029/2000GL012825, 2001.

Balachandran, N. K. and Rind, D.: Modelling the effects of UV variability and the $\mathrm{QBO}$ on the troposphere-stratosphere system. Part I: The middle atmosphere, J. Climate, 8, 2058-2079, 1995.

Balachandran, N., Rind, D., Lonergan, P., and Shindell, D. T.: Effects of solar cycle variability on the lower stratosphere and the troposphere, J. Geophys. Res., 104, 27321-27339, 1999.

Barnston, A. G. and Livezey, R. E.: A closer look at the effect of the 11-year solar cycle and the quasi-biennial oscillation on the Northern Hemisphere $700 \mathrm{mb}$ height and extratropical North American surface temperature, J. Climate, 2, 1295-1313, 1989.

Barnston, A. G. and Livezey, R. E.: Statistical prediction of JanuaryFebruary and mean Northern Hemisphere lower tropospheric climate from the 11-year solar cycle and the Southern Oscillation for west and east QBO phases, J. Climate, 4, 249-262, 1991.

Boberg, F. and Lundstedt, H.: Solar wind variations related to fluctuations of the North Atlantic Oscillation, Geophys. Res. Lett., 29, 1718, doi:10.1029/2002GL014903, 2002.
Boberg, F. and Lundstedt, H.: Solar wind electric field modulation of the NAO: a correlation analysis in the lower atmosphere, Geophys. Res. Lett., 30, 1825 doi:10.1029/2003GL017360, 2003.

Bochníček, J. and Hejda, P.: Association between extraterrestrial phenomena and weather changes in the Northern Hemisphere in winter, Surv. Geophys., 23, 303-333, 2002.

Bochníček, J. and Hejda, P.: The winter NAO pattern changes in association with solar and geomagnetic activity, J. Atmos. SolarTerr. Phys., 67, 17-32, 2005.

Bochníček, J., Hejda, P., Bucha, V., and Pýcha, J.: Possible geomagnetic activity effects on weather, Ann. Geophys., 17, 925-932, doi:10.1007/s00585-999-0925-4, 1999a.

Bochníček, J., Hejda, P., and Pýcha, J.: The effect of geomagnetic and solar activity on the distribution of controlling pressure formations in the Northern Hemisphere in winter, Studia Geophysica et Geodetica, 43, 390-398, 1999b.

Bucha, V. and Bucha Jr., V.: Geomagnetic forcing of changes in Climate and in the atmospheric circulation, J. Atmos. Terr. Phys., 60, 145-169, 1998.

Gimeno, L., de la Torre, L., Nieto, R., Garcia, R., Hernández, E., and Ribera, P.: Changes in the relationship NAO-Northern Hemisphere temperature due to solar activity, Earth Planet. Sci. Lett., 206, 15-20, 2003.

Gleisner, H. and Thejll, P.: Patterns of tropospheric response to solar variability, Geophys. Res. Lett., 30, 1711, doi:10.1029/2003GL017129, 2003.

Gray, L. J., Beer, J., Geller, M., Haigh, J. D., Lockwood, M., Matthes, K., Cubash, U., Fleitmann, D., Harrison, G., Hood, L., Luterbacher, J., Meehl, G. A., Shindell, D., van Geel, B., and White, W.: Solar influences on climate, Rev. Geophys., 48, RG4001, doi:10.1029/2009RG000282, 2010.

Haigh, J. D.: The role of stratospheric ozone in modulating the solar radiative forcing of climate, Nature, 370, 544-546, 1994.

Haigh, J. D.: The impact of solar variability on climate, Science, 272, 981-984, 1996.

Haigh, J. D.: The effects of solar variability on the Earth's climate, Philosophical Transactions of the Royal Society of London Series A-Mathematical Physical and Engineering Sciences, 361, 95-111, 2003.

Kodera, K.: The solar and equatorial QBO influences on the stratospheric circulation during the early Northern Hemisphere winter, Geophys. Res. Lett., 18, 1023-1026, doi:10.1029/90GL02298, 1991.

Kodera, K.: Solar influence on the spatial structure of the NAO during winter 1900-1999, Geophys. Res. Lett., 30, 1175, doi:10.1029/2002GL016584, 2003.

Kodera, K.: The role of dynamics in solar forcing, Space Sci. Rev., 125, 319-330, doi:10.1007/s11214-006-9066-1, 2006.

Kodera, K. and Kuroda, Y.: Dynamical response to the solar cycle, J. Geophys. Res., 107, D244749, doi:10.1029/2002JD002224, 2002.

Kodera, K. and Kuroda, Y.: A possible mechanism of solar modulation of the spatial structure of the North Atlantic Oscillation, J. Geophys. Res., 110, D02111, doi:10.1029/2004JD005258, 2005.

Kuroda, Y. and Kodera, K.: Effect of solar activity on the Polar-night jet oscillation in the northern and southern hemisphere winter, J. Meteorol. Soc. Japan, 80, 973-984, doi:10.2151/jmsj.80.973, 2002. 
Labitzke, K. and van Loon, H.: Association between the 11-year solar cycle, the QBO and the atmosphere. Part I: The troposphere and stratosphere in the Northern Hemisphere in winter, J. Atmos. Terr. Phys., 50, 197-206, 1988.

Li, Y., Lu, H., Jarvis, M. J., Clilverd, M. A., and Bates, B.: Nonlinear and nonstationary influences of geomagnetic activity on the winter North Atlantic Oscillation, J. Geophys. Res., 116, D16109, doi:10.1029/2011JD015822, 2011.

Lu, H., Jarvis, M. J., Graf, H.-F., Young, P. C., and Horne, R. B.: Atmospheric temperature response to solar irradiance and geomagnetic activity, J. Geophys. Res., 112, D11109, doi:10.1029/2006JD007864, 2007.

Lu, H., Clilverd, M. A., Seppälä, A., and Hood, L. L.: Geomagnetic perturbations on stratospheric circulation in late winter and spring, J. Geophys. Res., 113, D16106, doi:10.1029/2007JD008915, 2008a.

Lu, H., Jarvis, M. J., and Hibbins, R. E.: Possible solar wind effect on the Northern Annual Mode and Northern Hemispheric circulation during winter and spring, J. Geophys. Res., 113, D23104, doi:10.1029/2008JD010848, 2008b.

Lundstedt, H.: Influence of interplanetary interaction regions on geomagnetic disturbances and tropospheric circulation, Planet. Space Sci., 32, 1541-1545, 1984.

Marchand, M., Keckhut, P., Lefebvre, S., Claud, C., Cugnet, D., Hauchecorne, A., Lefevre, F., Lefebvre, M.-P., Jumelet, J., Lott, F., Hourdin, F., Thuillier, G., Poulain, V., Bossay, S., Lemennais, P., David, C., and Bekki, S.: Dynamical amplification of the stratospheric solar response simulated with the ChemistryClimate Model LMDz-Reprobus, J. Atmos. Solar-Terr. Phys., 75-76, 147-160, 2012.

Matthes, K., Kuroda, Y., Kodera, K., and Langematz, U.: Tranfer of the solar signal from the stratosphere to the troposphere: Northern winter, J. Geophys. Res., 111, D06108, doi:10.1029/2005JD006283, 2006.
Richmond, A. D. and Thayer, J. P.: Ionospheric electrodynamics: A tutorial, in: Magnetospheric Current Systems, edited by: Ohtani, S,-I., Fujii, R., Hesse, M., and Lysak, R. L., American Geophysical Union, Washington, D.C., pp. 131-146, 2000.

Rind, D. and Balachandran, N.: Modeling the effects of UV variability and the QBO on the troposphere-stratosphere system. Part II; The troposphere, J. Climate, 8, 2080-2095, 1995.

Seppälä, A., Randall, C. E., Clilverd, M. A., Rozanov, E., and Rodger, C. J.: Geomagnetic activity and polar surface air temperature variability, J. Geophys. Res., 114, A10312, doi:10.1029/2008JA014029, 2009.

Thejll, P., Christiansen, B., and Gleisner, H.: On correlations between the North Atlantic Oscillation, geopotential heights, and geomagnetic activity, Geophys. Res. Lett., 30, 1347, doi:10.1029/2002GL016598, 2003.

Thompson, D. W. J., Wallace, J. M., and Hegerl, G. C.: Annular modes in the extratropical circulation. Part II: Trends, J. Climate, 13, 1018-1036, 2000.

Thompson, D. W. J., Wallace, J. M. Kennedy, J. J., and Jones, P. D.: An abrupt drop in Northern Hemisphere sea surface temperature around 1970, Nature, 467, 444-445, 2010.

Tinsley, B. A.: Influence of solar wind on the global electric circuit, and inferred effects on cloud microphysics, temperature and dynamics in the troposphere, Space Sci. Rev., 94, 231-258, 2000.

van Loon, H. and Labitzke, K.: Association between the 11-year solar cycle, the QBO, and the atmosphere. Part II: Surface and $700 \mathrm{mb}$ in the Northern Hemisphere in winter, J. Climate, 1, 905920, 1988.

Woollings, T., Lockwood, M., Masato, G., Bell, C., and Gray, L.: Enhanced signature of solar variability in Eurasian winter climate, Geophys. Res. Lett., 37, L20805, doi:10.1029/2010GL044601, 2010. 